\title{
"NÓS NA REDE": PRIMEIROS DESDOBRAMENTOS DO PROJETO EXTENSIONISTA EM ODONTOLOGIA
}

\author{
Cristina Berger Fadel ${ }^{1}$ \\ Eunice Kuhn ${ }^{2}$ \\ Leomar Emanuel Almeida Mecca ${ }^{3}$ \\ Jean Erick Langoski ${ }^{4}$
}

\begin{abstract}
RESUMO: O projeto extensionista "Nós na rede: contribuições da Odontologia para educação, prevenção e manutenção da saúde" visa o acolhimento das demandas educativas, preventivas e curativas em saúde bucal da comunidade acadêmica da Universidade Estadual de Ponta Grossa, bem como à prevenção e à educação em saúde bucal coletiva destinada à comunidade externa em geral. O objetivo deste trabalho é expor os resultados de seu primeiro ano de implantação. As informações coletadas mostraram uma forte interação entre universidade e comunidade externa, por meio do desenvolvimento de parcerias institucionais $(\mathrm{n}=8)$, e também o acolhimento de necessidades em saúde bucal da comunidade acadêmica $(\mathrm{n}=60)$. Conclui-se que o presente projeto consiste em uma atividade extensionista eficiente e resolutiva, capaz de provocar rica experiência para todos os envolvidos.
\end{abstract}

PALAVRAS-CHAVE: Extensão comunitária. Saúde bucal. Educação em saúde.

"Nós na Rede": first developments of the extension project on Odontology

\begin{abstract}
The extension project "Nós na rede: contributions of Odontology to dental education, prevention and health maintenance" aims to meet the oral health educational, preventive and curative demands of the academic community of the State University of Ponta Grossa (State of Paraná, Brazil). It also aims to cope with oral health prevention and education actions for the general external community. This work aims to present the results of its first year of implementation. The information collected showed a strong interaction between the university and the external community, through the development of institutional partnerships $(\mathrm{n}=8)$, and also the meet of oral health needs of the academic community $(\mathrm{n}=$ 60). It was concluded that this project is an efficient and resolute extension activity, and also capable of providing valuable experiences for those who are involved in it.
\end{abstract}

KEYWORDS: Community extension. Oral health. Health education.

\section{INTRODUÇÃO}

Um dos maiores desafios das universidades brasileiras na atualidade constitui-se ainda na efetivação da indissociabilidade entre ensino, pesquisa e extensão, tema que assumiu

\footnotetext{
${ }^{1}$ Doutora em Odontologia Preventiva pela Universidade Estadual Paulista "Júlio de Mesquita Filho", professora adjunta da Universidade Estadual de Ponta Grossa (cbfadel@gmail.com).

${ }^{2}$ Doutora em Clínica Integrada em Odontologia pela Universidade Estadual de Ponta Grossa, professora assistente na mesma instituição (nice.kuhn@ig.com.br).

${ }^{3}$ Pós-graduando em Saúde Pública com ênfase em Saúde da Família, cirurgião-dentista (leo_mecca@hotmail.com).

${ }^{4}$ Graduando em Odontologia na Universidade Estadual de Ponta Grossa, bolsista no projeto de extensão "Nós na rede: contribuições da Odontologia para educação, prevenção e manutenção da saúde” (je-erick@hotmail.com). 
renovada importância a partir do momento que foi consagrado na Constituição Federal de 1988, nos termos do Art. 207.

As universidades gozam de autonomia didático-científica, administrativa e de gestão financeira e patrimonial, e obedecerão ao princípio de indissociabilidade entre ensino, pesquisa e extensão. (BRASIL, 1988).

Essas três esferas apresentam-se, no âmbito das universidades públicas brasileiras, como uma de suas maiores virtudes e expressão de compromisso social. O exercício de tais funções é requerido como dado de excelência no ensino superior, fundamentalmente voltado para a formação profissional à luz da apropriação e da produção do conhecimento científico (MARTINS, 2011).

Para Dias (2009), o princípio da indissociabilidade das atividades de ensino, pesquisa e extensão é fundamental no fazer acadêmico. A relação entre tais arranjos educacionais, quando bem articulados, conduz a mudanças significativas nos processos de ensino e de aprendizagem, fundamentando, didática e pedagogicamente, a formação profissional. Nesse caso, estudantes e professores constituem-se, efetivamente, em sujeitos do ato de aprender, de ensinar e de formar profissionais e cidadãos. Assim, pesquisa e extensão em interação com o ensino, com a universidade e com a sociedade, possibilitam operacionalizar a relação entre teoria e prática, a democratização do saber acadêmico e o seu retorno à universidade, testado e reelaborado.

Pela extensão, a comunidade acadêmica tem a possibilidade de, na sociedade, elaborar e vivenciar a práxis do conhecimento adquirido, promovendo uma postura que vai além da formação profissional do estudante. Ainda, propicia a ele uma visão mais globalizada de conhecimento, a partir da conscientização das realidades vivenciadas por diferentes comunidades e da compreensão do seu papel enquanto sujeito social (BIONDI; ALVES, 2011).

A extensão, entendida como prática acadêmica que interliga a universidade nas suas atividades de ensino e de pesquisa com as demandas da maioria da população, possibilita essa formação do profissional cidadão. As atividades extensionistas credenciam-se cada vez mais junto à sociedade como espaço privilegiado de produção do conhecimento significativo para a superação das desigualdades sociais existentes (BRASIL, 2010a). A experiência no campo da extensão universitária oportuniza o acompanhamento das condições de vida e de saúde das pessoas inseridas em sua realidade e a vivência de uma forma de atuação que não se limita à tradicional. Constitui, ainda, um importante agente no processo individual e coletivo de formação pessoal (FADEL; BORDIN; LANGOSKI, 2013).

Segundo Rodrigues (2006), pode-se perceber que, basicamente, sendo o papel da universidade produzir e transmitir conhecimento, a pesquisa - como lugar de produção de conhecimento e o ensino - como lugar de transmissão do conhecimento - estão significados e amplamente reconhecidos nas universidades brasileiras. Contudo, com relação à extensão, não há clareza sobre o seu significado, o seu papel no âmbito institucional e social, assumindo, em muitos casos, caráter de uma prática institucional unilateral, na qual a universidade, isoladamente, determina o perfil das ações a serem desenvolvidas junto à comunidade.

No entanto, a conceituação assumida pelo Fórum de Pró-reitores de Extensão das Universidades Públicas Brasileiras (FORPROEX), no final da década de 1980, expressa nitidamente o modo desejável de atuação institucional diante a sociedade em que se insere: 
produção e socialização do conhecimento, visando à priorização de intervenções na realidade das populações, retirando, assim, o caráter de terceira função da extensão e dimensionando-a como ação vinculada, política, estratégica e democratizante (BRASIL, 2001).

Silva et al. (2011) reafirmam que a extensão universitária deve constituir-se em um conjunto de ações de caráter educativo, relacional e interdisciplinar, promovendo a interação entre a universidade e a sociedade. Dessa forma, as atividades extensionistas devem ser capazes de transformar-se em um amplo canal pelo qual a universidade exerce sua função social e formadora, agregando aos afazeres conjuntos de estudantes, professores e servidores, em equipes multi e transdisciplinares.

Embora o reconhecimento legal dessa atividade acadêmica, com vistas a sua inclusão na Constituição Federal e no aparelhamento do FORPROEX tenha ocorrido há tempos, a maioria das ações realizadas enfoca o seu processo de construção histórica e a sua inserção dentro da Universidade como uma terceira função. Poucos são aqueles que investigam a prática dos seus projetos, seu dia a dia, sua influência no processo de formação dos discentes e sua contribuição para a consolidação de um campo de conhecimento específico e das consequências desses exercícios acadêmicos (CASTRO, 2004).

Nesse sentido, o objetivo deste trabalho foi investigar o resultado das práticas realizadas pelo projeto de extensão "Nós na rede: contribuições da odontologia para educação, prevenção e manutenção da saúde". O referido projeto é uma iniciativa do Departamento de Odontologia da Universidade Estadual de Ponta Grossa (UEPG). Suas ações buscam atenuar a carência de políticas de apoio voltadas à comunidade acadêmica da UEPG, especialmente em situação de vulnerabilidade social, e a sua comunidade externa, no âmbito da saúde bucal. Além disso, constitui uma de suas metas, oportunizar ao acadêmico de Odontologia uma vivência prática de atenção coletiva em saúde. Este projeto atua como instrumento viabilizador da Estratégia de Promoção da Saúde (BRASIL, 2010b), disseminando informações, com ênfase no emponderamento e na autonomia dos sujeitos, realizando ações de cunho educativo e preventivo em saúde bucal e acolhendo necessidades odontológicas curativas.

\section{MATERIAIS E MÉTODOS}

Após a aprovação do Comitê de Ética em Pesquisa da UEPG - Parecer 2.349/12, foi realizado um estudo descritivo. Essa foi a opção metodológica eleita para verificar os resultados do primeiro ano de implantação do referido projeto extensionista (abril de 2012 e abril de 2013), e, também, a análise de dados secundários produzidos pela população beneficiária deste projeto.

Os dados referentes ao atendimento clínico, prática dedicada exclusivamente à comunidade acadêmica da UEPG, foram obtidos por meio de um formulário individual e de um prontuário clínico. O formulário clínico foi aplicado pelo Centro de Auxílio e Orientação ao Estudante (CAOE) da própria instituição no momento da inscrição no projeto. Do formulário foram coletadas informações do público-alvo quanto a gênero, idade, curso, renda, estado civil, entre outras, e, ainda, a forma de conhecimento da existência do projeto, o motivo da busca pelo atendimento e a percepção da necessidade de saúde bucal. Tais informações tornaram possível o conhecimento do perfil socioeconômico e demográfico do público-alvo. 
O prontuário clínico, com dados relativos à saúde geral e bucal, foi construído para cada paciente e preenchido no primeiro contato com professores e acadêmicos participantes do projeto, realizado em ambiente odontológico próprio para atividades clínicas. Por meio dele, foram coletados dados amplos sobre saúde geral e específicos a respeito das condições de saúde bucal, como hábitos, condição dental e procedimentos realizados.

As atividades envolvendo a comunidade externa dizem respeito à disseminação de informações, por meio de ações educativas e preventivas em saúde bucal, como a apresentação de teatros lúdicos, jogos e vídeos educativos, palestras, escovação supervisionada e exame clínico bucal. Os dados inerentes a essas atividades foram coletados por relatórios diários de cada ação, elaborados por membros atuantes do projeto.

Todas as informações obtidas foram digitadas e organizadas em um banco de dados no programa Excel, analisadas e apresentadas em frequência relativa e absoluta.

\section{RESULTADOS}

Os resultados alcançados por essa experiência com a comunidade externa são esboçados em diferentes ciclos de vida. No âmbito infantil, a implicação é bastante positiva frente à utilização de instrumentos lúdico-pedagógicos, uma vez que conseguem atrair a atenção para temas de interesse, auxiliando na (re)definição de valores e na motivação para aquisição e manutenção da saúde bucal. Para adolescentes, a estratégia desenvolvida é a ruptura da hierarquia do saber técnico e a criação de vínculo afetivo pertinente a essa faixa etária, estabelecendo um campo de interação de ideias e opiniões para introdução de novos hábitos. Entre adultos e idosos, propõe-se uma participação mais ativa e consciente dos sujeitos, valorizando suas experiências individuais e particularidades, utilizando-se de propostas pedagógicas ajustadas às suas características e necessidades.

O número de participantes e as parcerias concretizadas pelo Projeto encontram-se abaixo descritos (Tabela 1).

Tabela 1 - População externa participante do projeto "Nós na Rede". Ponta Grossa-PR, 2012.

\begin{tabular}{cc}
\hline Número & Caracterização $\left(^{*}\right)$ \\
\hline 441 & $\begin{array}{r}\text { Crianças e adolescentes com idade entre 0 e 16 anos, } \\
\text { participantes do Projeto UEPG + ENERGIA: Festival de Saúde. } \\
\text { Público participante de feiras e eventos de saúde locais e } \\
\text { regionais. }\end{array}$ \\
50 & $\begin{array}{r}\text { Crianças regularmente matriculadas na Escola Sagrado Coração } \\
\text { de Jesus, Nova Rússia, Ponta Grossa/PR. }\end{array}$ \\
& $\begin{array}{r}\text { Alunos do ensino regular ( } 5^{\circ} \text { ano) e alunos com necessidades } \\
\text { educacionais especiais (Educação de Jovens e Adultos) } \\
\text { regularmente matriculadas na Escola Municipal Humberto } \\
\text { Cordeiro, Oficinas, Ponta Grossa/PR. }\end{array}$ \\
& População frequentadora do Terminal Central de Transporte \\
Urbano de Ponta Grossa/PR.
\end{tabular}


Fonte: Os autores (2013).

Em relação à comunidade acadêmica da UEPG, os resultados obtidos mostram o acolhimento de 60 acadêmicos, sendo $37(61,66 \%)$ pertencentes ao gênero feminino e $23(38,33 \%)$, ao gênero masculino, com a maioria (73,33\%) apresentando idade entre 17 e 25 anos. Com relação ao tipo do curso, houve a inserção de diferentes áreas de formação (Gráfico 1), sendo o próprio curso de Odontologia o mais frequente. Quanto ao tipo de tratamento, destaca-se a busca por cirurgias de terceiros molares inclusos.

Gráfico 1 - Distribuição da população acadêmica participante do projeto "Nós na Rede", segundo o tipo de curso. Ponta Grossa, 2012-2013.

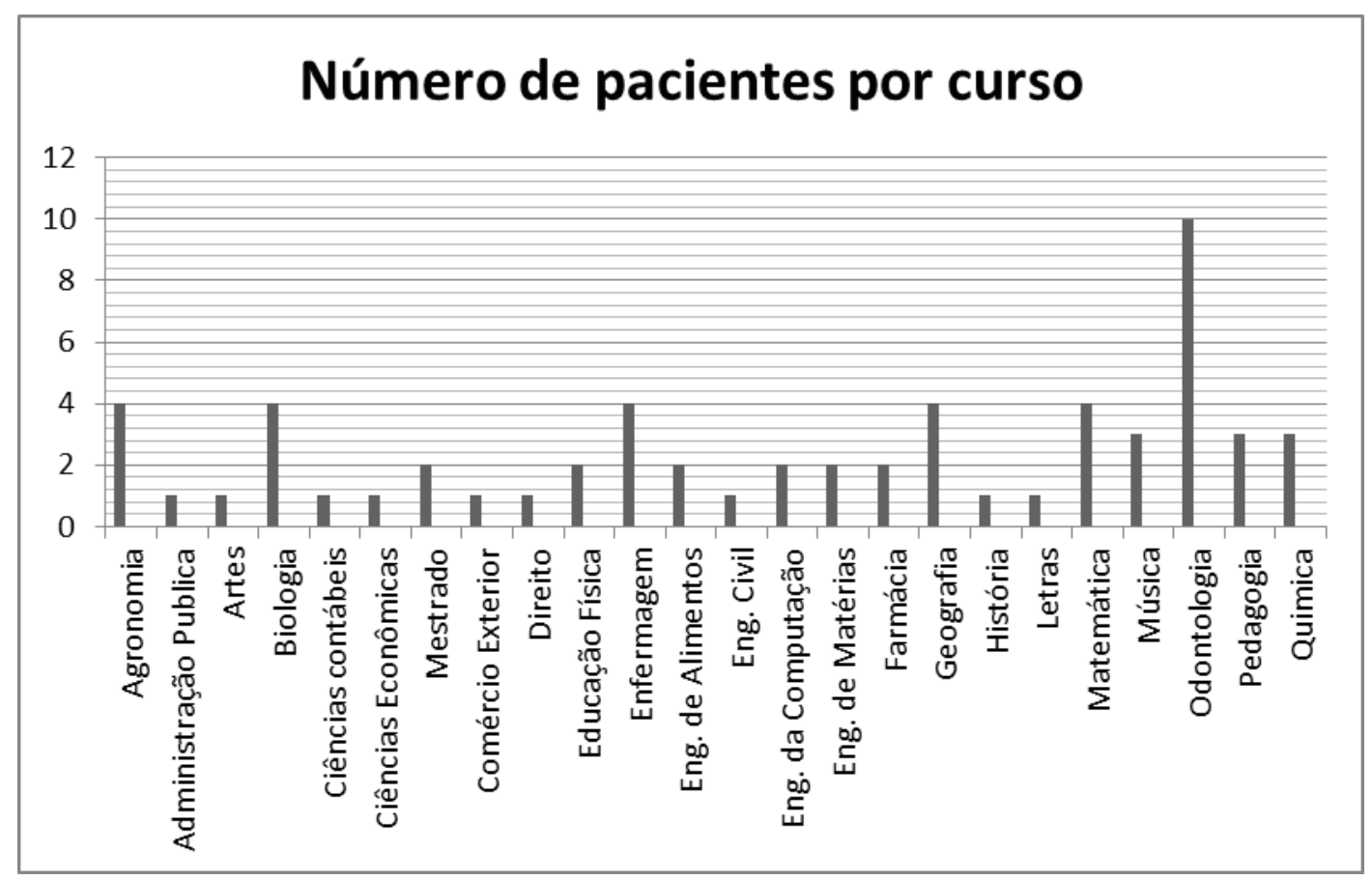

Fonte: Os autores (2013).

Segue, abaixo, descrição dos procedimentos clínicos realizados pela equipe discente e docente do projeto "Nós na rede" (Tabela 2).

Tabela 2 - Número de procedimentos clínicos realizados na população acadêmica participante do projeto "Nós na Rede." Ponta Grossa, 2012-2013.

\begin{tabular}{cl}
\hline $\begin{array}{c}\text { Número de } \\
\text { Procedimentos }\end{array}$ & Procedimentos Clínicos Executados \\
60 & $\begin{array}{l}\text { Instrumentalização em saúde bucal por meio de diálogo, manual impresso e } \\
\text { artefato audiovisual. }\end{array}$ \\
\hline
\end{tabular}


60 Avaliação da qualidade de saúde sistêmica e condição de saúde bucal.

Radiografia panorâmica como método completar a avaliação da condição dental.

42 Profilaxia e evidenciação de placa bacteriana.

25 Aplicação tópica de flúor.

03 Aplicação de selante dentário.

26 Tratamento restaurador convencional

26 Polimento de restauração.

16 Tratamento periodontal básico.

22 Exodontia de terceiros molares inclusos.

02 Encaminhamento às clínicas de especialidades.

Fonte: Os autores (2013).

\section{DISCUSSÃO}

As ações de educação em saúde bucal realizadas pelo projeto, com ênfase na disseminação do conhecimento e informação à sua comunidade externa, assumem e englobam parte da conceituação básica do processo extensionista, a qual se refere à produção e à socialização do conhecimento, visando à intervenção social.

As experiências expostas na Tabela 1 permitiram aos membros envolvidos, no binômio universidade/comunidade, o desenvolvimento de uma relação de respeito e aprendizado mútuo, não hierárquica, cooperativa e extremamente humanista. Revela-se, ainda, um espaço privilegiado, que permite ao acadêmico elaborar e vivenciar a prática de seus conhecimentos, compreendendo melhor o seu papel como sujeito social, intervindo na realidade, para a superação das desigualdades sociais existentes. Ressalta-se, também, por meio dessas práticas, a consolidação de um campo de conhecimento específico, integrando o trabalho conjunto de estudantes, professores e servidores.

As ações de educação em saúde bucal realizadas pelo projeto, com ênfase na disseminação do conhecimento e na informação à sua comunidade externa, assumem e englobam parte da conceituação básica do processo extensionista, a qual se refere à produção e socialização do conhecimento, visando a intervenção social. As experiências expostas na Tabela 1 têm permitido, aos membros envolvidos do binômio universidade/comunidade, o desenvolvimento de uma rica relação de respeito e aprendizado mútuo, não hierárquica, cooperativa e extremamente humanista. Revela-se ainda um espaço privilegiado, que permite ao acadêmico elaborar e vivenciar a prática de seus conhecimentos, compreendendo melhor o seu papel enquanto sujeito social, intervindo na realidade, para a superação das desigualdades sociais existentes. Ressalta-se também, por meio dessas práticas, a consolidação de um campo de 
conhecimento específico, integrando o trabalho conjunto de estudantes, professores e servidores.

Quanto à atuação junto à comunidade acadêmica (Tabela 2), os procedimentos clínicos realizados pelo projeto se enquadram nos conceitos da atenção básica em saúde, ou seja, um conjunto de ações, em nível individual ou coletivo, situadas no primeiro nível de atenção dos sistemas de saúde, voltadas para a promoção da saúde, a prevenção de agravos, o diagnóstico, o tratamento, a reabilitação e a manutenção da saúde (BRASIL, 2006). No âmbito da atenção básica, os resultados mostraram que a maioria dos procedimentos realizados nessa população foram resolutivos, uma vez que tende a atender os seus princípios ordenadores: o primeiro contato, a longitudinalidade, a integralidade ou abrangência e a coordenação (BRASIL, 2006).

Estes dados revelam que informações epidemiológicas válidas, podem ser obtidas pela análise dos levantamentos nacionais, no entanto, para o reconhecimento e o planejamento de ações locais de saúde apresentam limitações. Desta forma, evidencia-se aqui o grande valor de levantamentos epidemiológicos locais, como o realizado por este estudo, uma vez que os mesmos permitem o acesso a informações de saúde confiáveis, capazes de subsidiar ações em saúde (bucal), com ênfase no planejamento, execução e avaliação das práticas coletivas.

\section{CONSIDERAÇÕES FINAIS}

O projeto "Nós na rede" tem se mostrado eficiente na realização de ações voltadas à comunidade externa e resolutivo na atenção em saúde bucal à comunidade acadêmica, atendendo às diretrizes das práticas de extensão. Ainda, os resultados dessa experiência extensionista vêm nitidamente permitindo uma formação acadêmica mais humanizada e comprometida com a atenção básica na saúde e com a construção de vínculo entre participantes e comunidade, com maior possibilidade de troca de experiências e conhecimentos.

\section{REFERÊNCIAS}

ANDIFES. Perfil socioeconômico e cultural dos estudantes de graduação das universidades federais brasileiras. 2011. Disponível em: $<$ http://www.prace.ufop.b r/novo/pdfs/publicacoes/Relatorio\%20Nacional.pdf>. Acesso em: 12 jan. 2014.

BIONDI, D.; ALVES, G. C. A extensão universitária na formação de estudantes do curso de engenharia florestal - UFPR. Revista Eletrônica do Mestrado em Educação Ambiental. Rio Grande, v. 26, p. 209-224, 2011.

BRASIL. Constituição da República Federativa do Brasil. 1988. Disponível em: $<$ http://www.planalto.gov.br/ccivil_03/constituicao/constituicao.htm>. Acesso em: 20 fev. 2014.

. Ministério da Educação. Plano Nacional de Extensão Universitária. Fórum de Próreitores de Extensão das Universidades Públicas Brasileiras e SESU/MEC. 2000-2001. Disponível em: <http://www.port al.ufpa.br/docsege/Planonacionaldeextensaouniversitaria .pdf>. Acesso em: 26 fev. 2014. 
- Ministério da Saúde. SB-Brasil 2010: condições de saúde bucal da população brasileira 2010a. Disponível em: <http://conselho.saude.gov.br/ultimas_noticias/2010/img/ap resentacao_281210.pdf.>. Acesso em: 25 jan. 2014.

. Ministério da Saúde. Política Nacional de Promoção da Saúde. Brasília, DF: MS, $2010 \mathrm{~b}$.

. Ministério da Saúde. Secretaria de Atenção à Saúde. Cadernos de Atenção Básica. 2006. Disponível em: <http://www.planalto.gov.br/ccivil_03/constituicao/constituicao.htm>. Acesso em: 15 mar. 2013.

CASTRO, L. M. C. A universidade, a extensão universitária e a produção de conhecimentos emancipadores: ainda existem utopias realistas. 2004. 185f. Tese (Doutorado em Enfermagem) - Instituto de Medicina Social, Universidade do Estado do Rio de Janeiro, 2004.

DIAS, A. M. L. Discutindo caminhos para a indissociabilidade entre ensino, pesquisa e extensão. Revista Brasileira de Docência, Ensino e Pesquisa em Educação Física, Cristalina, v. 1, n.1, p. 37-52, 2009.

FADEL, C. B.; BORDIN, D.; LANGOSKI, J. E. A educação como prática viabilizadora da saúde bucal. Journal of the Health Sciences Institute, São Paulo, v. 31, n. 2, p. 136-140, 2013.

MARTINS, L. M. Ensino-pesquisa-extensão como fundamento metodológico da construção do conhecimento na universidade. 2011. Disponível em: $<$ http://www.umcp os.com.br/centraldoaluno/arquivos/16_09_2011_134/Ensino_pesquisa_extensao_como_funda mento_metodologico_da_construcao_do_conhecimento_na_universidade.pdf.>. Acesso em: 25 mar. 2014.

RODRIGUES, R. A extensão universitária como uma práxis. Em Extensão, Uberlândia, v. 5, n. 1, p. 84-88, 2006.

SILVA, F. D. et al. A responsabilidade social por meio da extensão universitária: análise dos resultados de um projeto de extensão da UFV/CRP. SEMINÁRIO DE ADMINISTRAÇÃO, 4., SEMINÁRIO DE CONTABILIDADE, 2., MOSTRA CIENTÍFICA, 1., 2011, Viçosa.

Submetido em 18 de julho de 2014.

Aprovado em 2 de setembro de 2014. 